\title{
Da Natureza Jurídica da Herança Jacente
}

\section{Agerson Tabosa Pinto}

Mestre em Ciência Política no IUPERJ Doutor em Direito do Estado na USP Professor titular da UFC, aposentado Professor do Curso de Direito da FA7 



\section{Da Natureza Jurídica da Herança Jacente}

\section{GINTRODUÇÃO}

Juristas de todas as épocas muito discutiram sobre o que seriam os bens deixados pelo defunto sem herdeiros necessários e ainda não incorporados ao patrimônio dos herdeiros voluntários. Por outras palavras, qual seria a natureza jurídica desses bens que, jazendo, ficavam fora de patrimônio individual? $\mathrm{Na}$ antiguidade clássica, o Direito Romano, ao longo de sua evolução, dera muitas e diferentes respostas, nenhuma, porém, plenamente satisfatória. No começo da Idade Média, mantinha-se a resposta do Direito Romano justinianeu. Somente a partir do século XIII é que o direito consuetudinário francês, apoiado no direito germânico, estabeleceu que a posse e o domínio dos bens hereditários se transmitiam, de imediato, do defunto para os seus herdeiros, quaisquer que fossem eles. Era o droit de saisine, que vai ser recepcionado, depois, pelos códigos civis modernos. Algumas dúvidas, incertezas e problemas desapareceram, mas não todos. A herança jacente vai mudar de conceito, mas permanecerá. Os bens hereditários não mais vão ser tidos como res nullius, ou res sine domino, ou como universitates rerum, com personalidade jurídica autônoma. Mas o direito sucessório continua sendo um jus universum, e a hereditas, uma res universalis, que reúne ativo e passivo, e tem para gerenciá-la, enquanto jacente, a figura do curador e o herdeiro, a seu turno, não pode suceder em bens singulares. Dividimos o núcleo de nosso trabalho em 3 partes. Na primeira, estudaremos a herança jacente no Direito Romano, em todos os períodos de sua evolução. Na segunda, mostraremos as mudanças básicas ocorridas em decorrência do droit de saisine. Por último, já no direito moderno, cuidaremos da recepção da herança jacente pelo direito brasileiro. 
Sempre que possível, procuramos identificar os posicionamentos, recorrendo às fontes e não apenas confrontando argumentos e teorias. Alargar a pesquisa para o direito comparado, como gostaríamos, seria tarefa para além dos limites desta comunicação e a que, por certo, nos faltariam engenho e arte.

\section{4aDesenVolvimento}

Como anunciado, vamos estudar a natureza jurídica da herança jacente começando com o Direito Romano. Em seguida, apontaremos a mudança de rumo que, ainda na Idade Média, tomou o direito sucessório, até chegarmos a contemplar a instituição tal qual se encontra na codificação civil brasileira de hoje.

\subsection{Direito Romano}

Herdeiro era o sucessor do falecido. Havia, em Direito Romano, três tipos de herdeiros, todos definidos, com muita precisão, por Justiniano: o herdeiro necessário, o herdeiro seu e necessário e o herdeiro estranho ou voluntário. ${ }^{1} \mathrm{O}$ herdeiro necessário era o escravo, que, instituído por testamento, tornava-se livre e herdeiro logo após a morte do testador, espontaneamente ou não. ${ }^{2}$

Herdeiros seus e necessários eram os descendentes do falecido (filho, neto, mulher in manu), que viveram sob seu pátrio poder. ${ }^{3}$ Eram herdeiros seus porque pertenceram à mesma família, à mesma casa (domus) do de cujus, foram, por assim dizer, co-proprietários do mesmo oriundo patrimônio. Eram necessários porque, em regra, não podiam declinar da herança, oriunda seja de sucessão testamentária, seja de sucessão ab intestato.

\footnotetext{
Institutas, 2,19, pr.: Heredes autem aut necessarii discuntur aut sui et necessarii aut extranei.

Institutas, 2,19, 1: Necessarius heres est servus, heres institutus ideo sic appellatus, quia sive velit, sive nolit omnimodo, post mortem testatoris protinus liber et necessarius heres fit. Vide também Gaio, Institutas, 2, 153 e Código, 6.27.

Institutas, 2,19,2: Sui et necessarii heredes sunt, vel uti filius, filia, nepos, neptisque ex filio, et deinceps ceteri liberi, qui modo in potestate morientis fuerint. Vide também Digesto, 28, 2,11, Paulo

Institutas, 2,19,3: Céteri qui testatoris júri subjecti non sunt, extranei heredes appellantur. Vide também Institutas de Gaio, 2,161 e Código Civil Brasileiro (CCB), art. 1789.
} 
Herdeiros estranhos eram os demais, familiares ou não, que não estiveram sob o poder do pater-familias testador. ${ }^{4}$ chamavam-se também voluntários porque, para assumir a nova qualificação, precisavam manifestar a adesão de sua vontade. ${ }^{5} \mathrm{Na}$ concepção dos romanos, a herança jazia ou estava estendida, relativamente aos herdeiros estranhos ou voluntários, pois, com relação aos herdeiros necessários não havia solução de continuidade entre a morte do de cujus, a delação ou abertura da sucessão e a aquisição ou adição dos bens hereditários pelos herdeiros. Segundo Bonfante, esses herdeiros "acquistano ipso jure la qualità di eredi e in conseguenza il patrimonio, anche senza loro saputa $\mathrm{e}$ contro la loro voluntà." ${ }^{6}$ Assim explica, com muita propriedade e clareza, César Rascón Garcia: "Cuando la aceptación de la herencia era voluntária, es decir, si el heres non era necessarius, desde el momento de la delación hasta el de la aceptación, la herencia estaba yacente (hereditas jacens), constituyendo un patrimonio cuyo titular se encontraba transitoriamente indeterminado, que podia sofrer incrementos o mermas" ${ }^{7}$ A delação (delatio) era o chamamento que se fazia com a abertura da sucessão seja testamentária ou legítima-decorrente do falecimento do hereditando. A adição (aditio) era a manifestação, simples ou solene, por parte do herdeiro, de que aceitava a herança. Esta era jacente durante o intervalo entre a delatio e a aditio. ${ }^{8}$ Mas, nesse intervalo de tempo, a quem pertenciam os bens que integravam a herança? Os bens hereditários representavam a pessoa do defunto ou a pessoa dos herdeiros? Eram res nullius ou formavam uma pessoa jurídica autônoma, como as fundações? Diferentes respostas foram dadas em diferentes momentos. Vamos considerá-las, cada uma de per si.

Institutas, 2,19,5. Vide também D., 28,7,12, Hermogeniano.

6 Bonfante, Pietro, Istituzioni di Diritto Romano, xa. ed., Giappichelli, 1951, p. 557.

7 García, César Rascón - Manual de Derecho Romano, 2ª ed., Tecnos, 1996, p. 235. É o que Arangio-Ruiz também destaca: “Dell'eredità non ancora adita dall'erede voluntari si dice que jace (onde l'espressione non clássica hereditas jacens). Istituzioni di Diritto Romano, 14ª .ed., Eugenio Jovene, 1991, p. 558

${ }^{8}$ D., 50, 16, 151. Terencio Clemente: Delata hereditas intelligitur quam quis possit adeundo consequi. Entende-se como aberta a sucessão, quando alguém pode fazer a adição da herança. 


\subsection{1. Época pré-clásica}

Os juristas dessa época, mais preocupados com as soluções casuísticas do que com as generalizações tóricas, costumavam dizer que os bens da herança jacente eram res nullius ou res sine domino, coisas de ninguém ou coisas sem dono, como, v. g., um animal selvagem. ${ }^{9}$ Essas coisas existem, mas não pertencem mais ao antigo dono, porque já morreu, nem aos seus futuros donos, ou porque são desconhecidos ou porque não aceitam a condição de herdeiros. As obrigações do de cujus, que fossem ambulatórias, perduravam, sem, porém, sujeito passivo, assim como o escravo, que fizesse parte da herança jacente, mantinha seu status de servus, embora estivesse, momentaneamente, sem dominus. Dois problemas, dentre outros, podem resultar dessa concepção. A herança jacente poderia ser dilapidada ou desaparecer, pois, pela ocupação (occupatio), quem se apodera de uma res nullius torna-se dela proprietário. Por falta de dono, a res nullius não podia ser objeto de furto nem podia ser protegida pela actio furti. ${ }^{10}$

\subsection{2. Época clássica}

Com o objetivo de equacionar os problemas apontados e proteger a herança jacente, em favor do herdeiro, várias soluções começam a ser articuladas.

\subsubsection{Representação da pessoa do defunto e do herdeiro}

Por uma ficção jurídica, a herança jacente, para não continuar sendo uma res nullius ou um patrimonium sine domino, passará a representar a

\footnotetext{
Jurisconsultos clássicos, em muitos fragmentos, registraram esse posicionamento, que, segundo Iglesias, eles não conseguiram superar. Iglesias, Juan, Derecho Romano $2^{a}$.ed., vol. II, Ariel, 1953, p. 283. Gaio, v.g., em D. 1, 8, 1, pr., diz que "res hereditariae, antequam aliquis heres existat, nullius in bonis sunt". E Ulpiano referese a um "successorium edictum idcirco propositum est ne bona hereditária vacua se domino diutius jacerent. D. 38,9,1, pr. Vide, ainda, de Ulpiano, D. 15,1,3, pr.; 38,9,1, pr. e 43,23, 13, 5 .

${ }^{10}$ Paulo diz que não se dá furto de coisas hereditárias, como também de coisas sem dono ... rei hereditariae furtum non fit, sicut nec ejus quae sine domino est... Digesto, $47,19,6$.
} 
pessoa do defunto ou do seu herdeiro. Assim, o acervo hereditário, como seu representante, prolongava a figura do seu titular anterior ${ }^{11}$ ou antecipava a titularidade do herdeiro futuro, ${ }^{12}$ dando continuidade, como diz Iglesias, entre la posición del difunto y la del heredero. ${ }^{13}$

\subsubsection{Crimen expilatae hereditatis}

Adriano (117-138) revogou o usucapio pro herede, instituto da época anterior, segundo o qual um terceiro, possuidor, mesmo de má fé, apenas por um ano, de herança não adida, tornava-se herdeiro. E Marco Aurélio ( 161 -180) instituiu o crimen expilatae hereditatis ${ }^{14}$ para punir quem, sem ser herdeiro, se apoderasse de herança jacente. A esta altura, a hereditas jacens não é mais uma res nullius, absolutamente sine domino. É antes um a res extra patrimonium, da qual existe um dominus virtual, o herdeiro. ${ }^{15}$

\subsubsection{Recurso à Lex Aquilia}

Coube ao herdeiro, hereditate jacente, para ressacir-se de prejuízos à sua futura herança, recorrer à Lex Aquilia. Fragmento de Ulpiano, apoiado em Celso, reporta-se ao exemplo do escravo assassinado, pertencente ao acervo hereditário. ${ }^{16}$ Noutro fragmento, fundamentado em Viviano e Labeão, Ulpiano reconhece legitimidade processual ao futuro herdeiro para recorrer aos interditos restitutórios cabíveis, em favor dos bens hereditários. ${ }^{17}$

${ }^{11}$ Institutas, 2,14,2: Nondum enim adita hereditas personae vocem sustinet non heredis futuri, sed defuncti ... Vide também Digesto, 41, 1, 33, 2, Juliano e 41, 1, 34, Ulpiano: Hereditas enim non heredis personam sed defuncti sustinet, ut multis argumentis juris civilis comprobatum est.

${ }^{12}$ D.,46,2,24, Pomponio: “ ... hic enim morte promissoris non extinguitur stipulatio, sed transit ad heredem cujus personam interim hereditas sustinet. Vide ainda Paulo, em Digesto, 3,5,21,1 e Hermogeniano, D., 41,1,61, pr.

Iglesias, Juan, cit., p. 283.

${ }^{14}$ Digesto., 47,19,1, Marciano e Código, 9,32

${ }^{15}$ Schulz observa que as res integrantes da herança jacente eram "res extra dominium y non meras cosas in domínio sin dueño". Schulz, Fritz, Derecho Romano Clásico (Classical Roman Law), Bosch, 1960, pp. 279-280.

${ }^{16}$ Digesto, 9,2,13,2, Ulpiano: Si servus hereditarius occidatur, quaeritur, quis Aquilia agat, quum dominus nullus sit hujus servi, et ait Celsus, legem domínio damna salva esse voluisse; dominus ergo hereditas habebitur, quare adita hereditate heres poterit experiri.

${ }^{17}$ Digesto, 43,24,13,5, Ulpiano 


\subsubsection{A figura do curador}

Para responder pela herança jacente, mesmo antes de ser considerada pessoa jurídica, o pretor podia nomear um curador, responsável por aquela universitas rerum, ainda não incorporada ao patrimônio dos herdeiros. ${ }^{18}$

\subsection{3. Época pós-clásica}

A tendência à generalização levou à concepção da herança jacente, como pessoa jurídica ou sujeito de direito abstrato, como já, por ficção, era reconhecida a personalidade jurídica da corporação (universitas personarum) e da fundação (universitas rerum). ${ }^{19}$ Por várias razões, essa concepção a que chegou a jurisprudentia romana, em sua fase final, não foi bem vista pelos romanistas. Iglesias, por exemplo, afirma que ela "no es afortunada ... Si se considera la herencia como persona jurídica, será menester entender - y tal no cabe - que el heredero no sucede, de modo directo e inmediato, al causante, sino que recibe por intermédio de la entidad hereditária autonoma. ${ }^{20}$

Embora se reconheçam procedentes as reservas feitas à teoria justinianeia, forçoso é reconhecer também a existência, na herança jacente, de alguns pressupostos da pessoa jurídica, do tipo universitas rerum. O conjunto dos bens hereditários, formando um todo (res universalis), distinto de suas partes, podendo sofrer acréscimos e diminuições, seria um deles.

${ }^{18}$ Digesto, 42, 4,8, Ulpiano: Si diu incertum sit, heres extiturus, nec ne sit, causa cogniti permitti oportebit, bona rei servandae causa possideri; et si ita res urgeat vel conditio bonorum, etiam hoc erit concedendum, ut curator constituatur.

${ }^{19} \mathrm{O}$ fragmento de Florentino (D., 30,116,3) ainda alude à pessoa do defunto, representada pela herança - hereditas personae defuncti, qui eam reliquit, vice fungitur e o de Paulo refere-se à pessoa indeterminadamente: ... hereditatem in quibusdam vice personae fungi receptum est... Mas, outro fragmento de Florentino, tido como interpolado, ao atribuir personalidade à herança jacente, é de uma clareza meridiana: "hereditas personae vice fungitur, sicut municipium, et decuria et societas". D., 46,1,22.

${ }^{20}$ Iglesias, Juan, cit., 285. Fritz Schulz refere-se com menoscabo a "esta absurda idea (que) llenó los textos clasicos, valiéndose para ello de las consabidas interpolaciones". Schulz, Fritz, cit., p. 281. Biondo Biondi conclui que "la costruzione justinianea una costruzione assai infelice, ripudiata concordemente della doctrina". Biondi, Biondo, Istituzioni di Diritto Romano, 4a. Ed., Giuffrè, 1972, p. 642. Fazendo coro com os romanistas estrangeiros, Moreira Alves considera inconsistente a concepção do Direito romano pós-clássico. Moreira Alves, José Carlos, Direito Romano, vol. II, 3a. ed., Rio de Janeiro, Forense, 1980, p. 508 
Outro pressuposto seria o fim ou destinação desses bens, ou sua incorporação ao patrimônio dos herdeiros voluntários, logo que identificados e manifestada sua aceitação. Para que a herança alcance sua destinação, necessário se faz protegê-la. Destituída de capacidade de fato, como toda pessoa jurídica, a herança jacente seria representada pelo seu curador, em benefício de todos os interessados em sua conservação. O tempo de atuação do curador podia ser muito pouco, não importa, pois em outras circunstâncias, sua representação também era por demais efêmera.

\subsection{Direito Medieval}

Perdurou, por quase toda a Idade Média, a concepção da herança jacente do direito romano pós-clássico, até o surgimento do droit de saisine, oriundo do direito consuetudinário francês e do direito germânico.

\subsubsection{Pessoa Jurídica autônoma}

O prestígio da compilação de Justiniano, à época, era tão grande, que sua concepção de herança jacente, como pessoa jurídica, permaneceu intocável por vários séculos. Autores acham, como Kaser, que os juristas clássicos e até os pós-clássicos "non intentaran una construcción dogmática de la herencia yacente". E quando dizem que a herança ocupa o lugar da pessoa (hereditas vice personae fungitur)" tales afirmaciones no son, en realidad, outra cosa que simples intentos para llegar a una concepcción general. "E conclui que só no direito medieval ou commune é que "la herencia yacente es concebida como sujeto de derecho independente (persona jurídica)." 21

Ao que parece, Iglesias segue a mesma linha de argumentação, quando afirma que a concepção justinianéia não pode ser considerada a preferida nem mesmo pelos compiladores do Corpus Juris Civilis. ${ }^{22}$

\subsubsection{Droit de Saisine}

Coube a um costume de Paris, também em vigor naAlemanha, conhecido como droit de saisine", romper uma tradição já multissecular de atribuir à herança jacente personalidade jurídica. Era o direito consuetudinário local sobrepondo-se ao jus commune, em uso nas comunidades, em

${ }^{21}$ Kaser, Max - Derecho Romano Privado, tradução da 5a . edição alemã de José Santa Cruz Teijeiro, Réus, 1982, p. 329

${ }^{22}$ Iglesias, Juan, cit., p. 285 
geral. Segundo esse direito, os herdeiros, mesmo os desconhecidos, entravam na posse e propriedade da herança imediatamente após a morte do de cujus, assim como os bens do servo morto passavam de imediato aos seus herdeiros. ${ }^{23} \mathrm{O}$ momento da abertura da sucessão era o mesmo da aquisição da herança pelos herdeiros. O intervalo, na sucessão dos herdeiros voluntários, entre a delatio (o chamamento) e a aditio (a aceitação) também desapareceu, sem que, em momento algum, a herança ficasse sem titular, sendo dispensável o recurso à ficção da pessoa jurídica. Para o instituto em tela, encerrava-se, aqui, a tradição do Direito Romano.

\subsection{Direito Moderno}

Os códigos modernos, desde o Código Francês, de 1804, abandonaram a concepção romana justinianéia de herança jacente como pessoa jurídica (universitas rerum $)^{24}$ e recepcionaram o direito consuetudinário germano-gaulês do droit de saisine. ${ }^{25}$

\subsection{Direito Brasileiro}

Vamos estudar a natureza jurídica da herança jacente no direito brasileiro, ao longo de duas fases. A primeira, anterior à codificação, vai da independência do Brasil até 1916, data da promulgação do nosso primeiro código civil; e a segunda, que se coloca no intermezzo entre os dois códigos, ou seja, de 1916 a 2002.

\subsubsection{Ordenações Filipinas}

Até o Alvará de 9 de novembro de 1754, o direito luso das Ordenações Filipinas mantinha a sistemática romana da personificação da herança jacente, posição ainda defendida no Brasil por juristas de renome, como

${ }^{23}$ A praxe, cuja fórmula dizia - le serf mort saisit le vif - constava de Aviso do Parlamento de Paris. Pereira, Caio Mário da Silva, Instituições de Direito Civil, VII, Direito das Sucessões, 12 ed., Forense, 1998, p. 13

${ }^{24} \mathrm{Nel}$ diritto moderno l'adizione è sparita e i beni del defunto passano immediatamente nell 'erede chiamato", Bonfante, Pietro, cit., Clovis Bevilaqua observa também que "o direito moderno dispensa essa ficção ( da pessoa jurídica), que se não ajusta com a concepção da transmissão imediata da heranção aos que a ela tiverem direito". Bevilaqua, Clovis, Código Civil dos Estados Unidos do Brasil, VI, Francisco Alves, 1958, p. 31.

${ }^{25}$ O Código de Napoleão diz, em seu art. 724, "que os herdeiros legitimos, naturais e o cônjuge sobrevivente "sont saisit de plein droit des biens, droits et actives du defunt..." No art. 218, estabelece que a sucessão se abre com a morte natural e pela morte civil", e, no 777, que o efeito da aceitação remonta ao dia da abertura da sucessão”. Cf. Code Civil, Dalloz, 2000, pp. 598, 559 e 614. 
Teixeira de Freitas e Lacerda de Almeida. ${ }^{26}$ Outros, porém, contra ela se manifestavam, apoiados no “droit de saisine”, já referido. ${ }^{27} \mathrm{O}$ Alvará acima citado que, estabelecia que, aberta a sucessão, a propriedade e a posse civil da herança passavam de imediato aos herdeiros, representa, segundo Caio Mário, marco importantíssimo na evolução do nosso direito sucessório. ${ }^{28}$

\subsubsection{Código Civil de 1916}

Lei $\mathrm{n}^{\mathrm{o}} 3.071$, de $1^{\mathrm{o}}$-1-1916. O Código reservou apenas dois artigos para a herança jacente, os artigos 1591 e 1592. no 1591, alinha as hipóteses em que ocorre a herança jacente, na sucessão legítima ou $a b$ intestato:

"Não havendo testamento, a herança é jacente, e ficará sob a guarda, conservação e administração de um curador:

I. se o falecido não deixar cônjuge, nem herdeiros, descendente ou ascendente, notoriamente conhecido;

II. se os herdeiros, descendentes ou ascendentes, renunciarem a herança, e não houver cônjuge, ou colateral sucessível, notoriamente conhecido" ${ }^{29}$ No art. 1592, relaciona as hipóteses em que a herança também ficará jazendo:

"Havendo testamento, observar-se-á o disposto no artigo antecedente:

I. se o falecido não deixar cônjuge, nem herdeiros descendentes ou ascendentes;

II. se o herdeiro nomeado não existir ou não aceitar a herança;

III. se, em qualquer dos casos previstos nos dois números antecedentes, não houver colateral sucessível, notoriamente conhecido

IV. se, verificar algumas das hipóteses dos três números anteriores, não houver testamenteiro nomeado, o nomeado não existir, ou não

\footnotetext{
${ }^{26}$ Pereira, Caio Mário da Silva, cit., I, p. 201 e VI, pp. 12-14

${ }^{27}$ Vide Ordenações, livro 3, título $80, \S 1^{\circ}$. Segundo Carvalho Santos, “ o mesmo conceito de jacente atribuía também a Ord., livr. 3 , tit. $80, \S 1^{\circ}$, à herança enquanto não era adiada (sic), determinando positivamente: jazendo a herança por partir entre eles. No direito hodierno, já não são aceitáveis essas ficções”. Carvalho Santos, J.M. de Repertório Enciclopédico do Direito Brasileiro, XXIV, Borsoi, s/d,p. 354.

${ }^{28}$ Pereira, Caio Mário da Silva, cit., VI, p. 13.

${ }^{29}$ Brasil, Código Civil Comparado, Saraiva, 2002, p. 244
} 
aceitar a testamentária. ${ }^{30}$ Ao comentar o conceito do instituto como acolhido pelo Código, de cujo projeto foi autor, Bevilaqua observa que herança jacente é aquela cujos herdeiros ainda não são conhecidos. Difere a jacência no direito pátrio e no romano, porque neste, a herança jacente ainda não foi adida, mas espera-se que o seja ... Em direito pátrio, o herdeiro, ainda que desconhecido, adquire a propriedade e a posse dos bens da herança, desde a abertura da sucessão. Além disso, a herança jacente era considerada pessoa jurídica" ${ }^{31}$ o que seria, então, a herança jacente? Para Caio Mário, " no (direito) moderno, a doutrina é pacifica no sentido de não lhe reconhecer personalidade jurídica, Acrescentamos com Brinz e Zittelmann" que ela não representa o defunto nem os herdeiros. É uma universilidade, sem qualidade para agir, adquirir direitos e contrair obrigações". ${ }^{32}$ Para Orlando Gomes, "um patrimônio que a lei mantém unido, sob administração alheia, provisoriamente, para conservar a continuidade das relações. Um patrimônio sem dono atual, representado por um curador". ${ }^{33}$ Segundo Sílvio Rodrigues, "trata-se apenas de massa de bens despersonalizada, que não convém deixar ao abandono". ${ }^{34}$

\subsubsection{Código Civil de 2002}

Lei n ${ }^{\circ} 10.406$, de 10-1-2002. O novo Código Civil reuniu num só artigo o que dispunham os dois artigos do código anterior. Artigo 1819: "falecendo alguém sem deixar testamento nem herdeiro legítimo notoriamente conhecido, os bens da herança, depois de arrecadados, ficarão sob a guarda e administração de um curador, até a sua vacância". ${ }^{35}$ A nova redação ganhou, por certo, em concisão, clareza e precisão, daquela do diploma de 1916. Ao que parece, teria sido ela inspirada no projeto original de Clovis Bevilaqua. ${ }^{36}$

\footnotetext{
${ }^{30}$ Idem, ibidem, p. 244

${ }^{31}$ Bevilaqua, Clovis, cit., 31.

${ }^{32}$ Pereira, Caio Mário da Silva, cit., VI, p. 38.

${ }^{33}$ Gomes, Orlando - Sucessões, $7^{\text {a }}$. ed., Forense, 1998, p. 72

${ }^{34}$ Rodrigues, Sílvio-Direito Civil, VII, Direito das Sucessões, Saraiva, 2002, p. 82.

${ }^{35}$ Brasil - Novo Código Civil. Exposição de Motivos e Texto sancionado, Senado Federal, 2003, p. 314.

${ }^{36}$ Eis como foi redigido o artigo 1759 do projeto Bevilaqua: " Sempre que os herdeiros legítimos ou instituídos não forem conhecidos ou se acharem ausentes, o juiz competente procederá à arrecadação e inventário dos bens da herança, e não havendo funcionários que a isso incumba, nomeará quem os administre, até que sejam entregues aos seus donos ou que sejam declarados vacantes”. Cf. Rodrigues, Sílvio, cit., p. 82.
} 
O novo diploma legal nada acrescentou, relativamente à matéria em apreço, ao que já dispunha o anterior. O conceito de herança jacente permaneceu o mesmo, como são as mesmas as hipóteses de sua incidência. Quanto à sua natureza jurídica, a herança jacente continua destituída de personalidade, por lhe faltarem vários pressupostos, como previsão legal, objetivo com duração certa e estabilidade dos bens. Para Silvio Venosa, "como existe um administrador na herança jacente, na pessoa do curador ... a exemplo de outras entidades que não são jurídicas, como a massa falida, o condomínio em unidades autônomas, a herança jacente deve ser classificada como uma entidade com personalidade anômala" ${ }^{37}$ Segundo Zeno Veloso, trata-se de massa patrimonial despersonalizada, podendo atuar em juizo como autora ou ré, representada pelo curador (CPC, art. 12, IV), possuindo, na linguagem dos processualistas, personalidade judiciária". ${ }^{38}$

\section{[1] Conclusões}

3.1. Para os romanos, a herança ou o conjunto de bens, direitos e deveres, deixados pelo falecido para os seus herdeiros, sempre foi considerada uma res universalis e indivisível. Se, com a morte do hereditando, existem herdeiros necessários, não havia problemas com a sucessão, pois eles adquiriam, de imediato, a posse e a propriedade da herança.

3.2. Se, porém, só houvesse herdeiros estranhos ou voluntários, o seu consentimento para assumir o novo papel era conditio sine qua non para a adição, ou seja, a incorporação dos bens hereditários ao seu patrimônio. Abria-se, então, um intervalo entre o chamamento à sucessão e a adição da herança, durante o qual, diziam os textos, hereditas jacet, a herança ficava jazendo, estendida, sem dominus, actualiter, pois o anterior não era mais, e o futuro ainda não era. Nessa situação, a herança seria uma res nullius, e, como tal, podia facilmente, reduzir-se e até extinguir-se, acarretando prejuízos os mais diversos.

${ }^{37}$ Venosa, Sílvio de Salvo - Direito Civil - Direito das Sucessões, $3^{\text {a }}$. ed., Atlas, 2003, p. 62. Esta é também a posição doutrinária de Washington de Barros Monteiro, Maria Helena Diniz e Giselda Hironaka. Vide Hironaka, Giselda, in Azevedo, Antonio Junqueira(coord.), Comentários ao Código Civil, v. 20, Saraiva, 2003, p. 170.

${ }^{38}$ Veloso, Zeno, in Fiúza, Ricardo (coord.) Novo Código Civil comentado, 2a . ed., Saraiva, 2004,p. 1692. 
3.3. O direito precisava proteger a herança, em favor dos herdeiros e credores e a forma mais simples e prática encontrada pelos jurisconsultos foi a da pessoa fictícia, de atribuir-se personalidade aos bens hereditários, como já tinham personalidade os bens que constituíam as fundações (universitates rerum).

3.4. A forma do direito romano de garantir a proteção da herança jacente continuou sendo adotada pelo jus commune medieval até que, pelo século XIII, o direito consuetudinário franco-germânico apelou para outra ficção, a de que todo herdeiro, conhecido ou não, imediatamente se apoderava da herança, quando da morte do de cujus. Na prática , com o desaparecimento do intervalo entre a abertura da sucessão e a adição da herança, desapareceu também a jacência. Era o advento do chamado droit de saisine.

3.5. Com o Alvará de 1754, confirmado pelo Assento de 1786, o direito sucessório luso-brasileiro passou a adotar também do princípio da saisine. Assim é que o primeiro Código civil brasileiro, estabeleceu que, "aberta a sucessão, o domínio e a posse da herança transmitemse, desde logo, aos herdeiros legítimos e testamentários" (art. 1572), e, com relação à herança jacente, que ela "ficará sob a guarda, conservação e administração de um curador". (art. 1591).

3.6. O novo código, de 2002, não trouxe nenhuma novidade ao instituto, embora tenha melhorado o texto legal, em clareza e precisão. A herança jacente continua sendo um universo de bens, direitos e obrigações, autônomo e indivisível, sem personalidade jurídica, gerenciado pelo curador, aguardando ser incorporado ao patrimônio dos herdeiros, ou, na falta destes, ao patrimônio público. 


\section{Bibliografia}

ARANGIO-RUIZ, Vincenzo. Istituzioni di Diritto Romano. 14 ed., Eugenio Jovene, 1991.

BEVILAQUA, Clovis. Código Civil dos Estados Unidos do Brasil, VI, Francisco Alves, 1958.

B. BIONDI. Istituzioni di Diritto Romano. 4 ed., Giuffrè, 1972.

BONFANTE, Pietro. Istituzioni di Diritto Romano, xa. ed., Giappichelli, 1951.

Brasil - Novo Código Civil. Exposição de Motivos e Texto sancionado, Senado Federal, 2003. Brasil, Código Civil Comparado, Saraiva, 2002.

Cuerpo del Derecho Civil, edição bilíngüe facsimilar, (latim e espanhol) de Ildefonso L. García del Corral, Editorial Lex Nova, edição original, Jaime Molinas, editor, 1889.

França, Code Civil, Dalloz, 2000.

GARCÍA, César Rascón. Manual de Derecho Romano, 2 ed., Tecnos, 1996.

GOMES, Orlando. Sucessões, 7 ed., Forense, 1998.

HIRONAKA, Giselda - in Azevedo, Antonio Junqueira(coord.), Comentários ao Código Civil, v. 20, Saraiva, 2003.

IGLESIAS, Juan. Derecho Romano, 2 ed., vol. II, Ariel, 1953.

KASER, Max. Derecho Romano Privado, tradução da $5^{\text {a }}$ edição alemã de José Santa Cruz Teijeiro, Réus, 1982.

MOREIRAALVES, José Carlos, Direito Romano, vol. II, $3^{\mathrm{a}}$ ed., Forense, 1980.

PEREIRA, Caio Mário da Silva. Instituições de Direito Civil, VII, Direito das Sucessões, 12 ed., Forense, 1998. 
RODRIGUES, Sílvio. Direito Civil, VII, Direito das Sucessões, Saraiva, 2002.

SCHULZ, Fritz. Derecho Romano Clásico (Classical Roman Law), Bosch, 1960 .

VELOSO, Zeno. in Fiúza, Ricardo (coord.) Novo Código Civil comentado, 2 ed., Saraiva, 2004.

VENOSA, Sílvio de Salvo. Direito Civil - Direito das Sucessões, 3 ed., Atlas, 2003. 